\title{
Lead and the mitochondrion
}

\author{
Michael R. MoORe \\ B.Sc., Ph.D. \\ University Department of Materia Medica, Stobhill Hospital, Glasgow
}

\begin{abstract}
Summary
In studies on the distribution of lead in rats given drinking water containing lead acetate at concentrations: $0,100,500,1000$ and $5000 \mu \mathrm{gPb} / \mathrm{l}$ for one year, no change was observed in the organ distribution of lead, or in the subcellular distribution of lead in the organelles in the heart.

The mitochondrial enzyme, ferrochelatase, was significantly depressed in both the 500 and $1000 \mu \mathrm{g} / \mathrm{l}$ groups as was the cytoplasmic enzyme $\delta$-aminolaevulinic acid dehydratase. These depressions of enzyme activity were associated with ultrastructural changes in the myocardium after six months, and were most pronounced in the mitochondria.
\end{abstract}

\section{Introduction}

It has been recognized for some time that lead is bound within the cell to organelles and to proteins. This binding is thought principally to occur at sulphydryl sites on the protein such as is found in its binding to haemoglobin (Barltrop and Smith, 1972). Lead inhibits enzymes which are sulphydryl dependent such as $\delta$-aminolaevulinic acid (ALA) dehydratase (EC 4.2.1.24) and ferrochelatase (EC 4.99.1.1.) on the haem biosynthetic pathway and lipoamide dehydrogenase which is an essential component of the pyruvate and $\alpha$-ketoglutarate decarboxylase systems. The metabolic components most affected by lead would appear to be the formation of the respiratory pigments (haem and the cytochromes), energy production through inhibition of mitochondrial respiration and phosphorylation, and membrane transport through inhibition of $\mathrm{Na}^{+} \mathrm{K}^{+}$ATPase (Hasan et al., 1967).

Within the cell, lead would appear to be bound principally to the particulate fractions, although the actual distribution would seem to be organ-dependent. The results on this are equivocal. In the liver, however, the distribution favours the mitochondria and this mitochondrial lead would appear to be particularly stable (Castellino and Aloj, 1969). Little lead is found in the lysosomes (Barltrop, Barrett and Dingle, 1971) and in confirmation of this, Secchi, Alessio and Spreafico (1971) found elevated activities of mitochondrial and cytoplasmic serum enzyme markers with no change in lysosomal enzyme markers.

The changes in the activity of mitochondrial enzyme activity may be associated with leadinduced accumulation of iron within the mitochondria, as shown electronmicroscopically by Bessis and Breton Gorius (1959); Edwards and Elliot (1973) have shown activation of ALA synthetase by lead (EC 2.3.1.37) in vitro, this possibly being a function of depressed haem levels, followed by induction of this enzyme. This enzyme is activated by ferrous iron at low concentrations but inhibited at higher concentrations (Morrow, Urata and Goldberg, 1969).

The association of increased mortality due to ischaemic heart disease and soft water supplies has been recognized for some time. In sixty towns ino England and Wales, Stitt et al. (1973) showed a linear relationship between water hardness and cardiovascular mortality. The factors causing this are unknown but not necessarily due to water hardness itself. In towns with soft water supplies there is a much higher plumbosolvency of the water than in hard water areas (Moore, 1973); Beattie et al. (1972) have shown that there is a significant correlation between blood lead levels and lead levels in water from lead plumbing systems in such a soft water area, Glasgow. For these reasons lead must be considered in the aetiology of increased cardiovascular mortality in soft water areas.

These experiments describe the intracellular distribution of lead within the myocardium and describe the effect of this lead on two mitochondrial enzymes and upon the mitochondrial structure, viewed electronmicroscopically.

\section{Materials and methods}

Four groups of twelve Sprague Dawley rats, weighing $250 \mathrm{~g}$ at the beginning of the experiment, were used in these experiments. The drinking water for these groups, supplied ad libitum, contained, respectively, $0,100,500$ and $1000 \mu \mathrm{g} / \mathrm{l}$ of lead as lead acetate. These corresponded to the levels found previously in drinking water in Glasgow. The duration of the experiment was 1 year. All animals 
were killed by cervical dislocation followed by exsanguination.

Lead analysis was carried out on blood, liver, heart, kidney and bone (femur). Tissue leads were measured polarographically after wet digestion in concentrated nitric/sulphuric acid or by flameless atomic absorption spectrophotometry and the results expressed as $\mu \mathrm{g}$ lead/g wet weight tissue. Bone leads were determined on bone ash after dry ashing in a muffle furnace at $350^{\circ} \mathrm{C}$ for $8 \mathrm{hr}$ in silica crucibles with lids. Results were expressed as $\mu \mathrm{g}$ lead/g bone ash. All glassware in these experiments was washed overnight in $50 \%$ analar nitric acid, followed by ten rinses in distilled water.

Hepatic ALA synthase was measured by the method of Dowdle, Mustard and Eales (1967). Hepatic and cardiac ALA dehydratase was measured

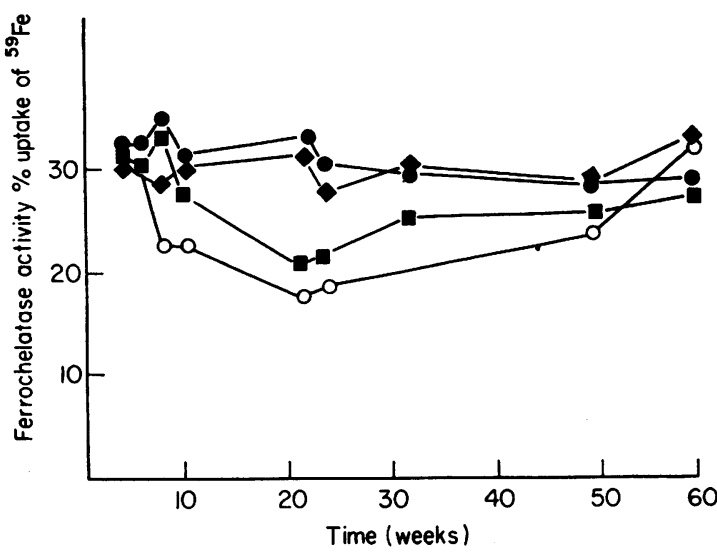

FIG. 1. Cardiac ferrochelatase activities in the four groups of rats subjected to chronic lead exposure and studied over 1 year. Lead levels: $>, 100 \mu \mathrm{g} / 1 ; \bigcirc, 1000$ $\mu \mathrm{g} / \mathrm{l} ; 0,20 \mu \mathrm{g} / \mathrm{l} ; \mathrm{\square}, 500 \mu \mathrm{g} / \mathrm{l}$. by the method of Moore et al. (1971). Ferrochelatase activity in heart and liver was measured by the incorporation of ${ }^{59} \mathrm{Fe}$ protoporphyrin to form haem by the method of Goldberg et al. (1956), results being expressed as per cent uptake of ${ }^{59} \mathrm{Fe}$.

In isotope uptake studies, $1 \mathrm{ml}$ of a solution of ${ }^{203} \mathrm{~Pb}$ chloride was administered orally to each rat. ${ }^{203} \mathrm{~Pb}$ was kindly supplied by the MRC Cyclotron Unit, Hammersmith Hospital, London. After dosage, the rats were counted in plastic containers in an IDL/Echo double probe $\gamma$ counter at set time intervals over 2 weeks against a 'phantom'. Fractions obtained by differential centrifugation were counted on a Wallac 3 inch crystal auto $\gamma$ counter.

Small fragments of papillary muscle for electronmicroscopy were fixed in $2 \%$ phosphate-buffered

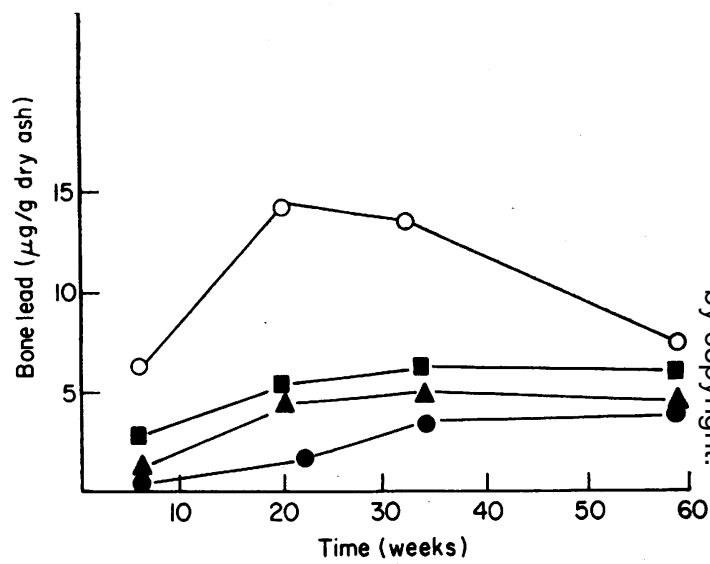

Fig. 2. The variation in bone lead of rats after chronic lead exposure over the period of the experiment. Bone leads were measured on the femur and are expressed as $\mu \mathrm{g} \mathrm{Pb} / \mathrm{g}$ bone ash. Water lead levels: $\bigcirc, 1000 \mu \mathrm{g} / \mathrm{l}$; $500 \mu \mathrm{g} / \mathrm{l} ; \Lambda, 100 \mu \mathrm{g} / 1 ; \bigcirc$, normal water $20 \mu \mathrm{g} / 1$.

TABLE 1. Enzyme activities and lead levels in rats treated with lead at $1000 \mu \mathrm{g} / \mathrm{litre}$ Time (weeks)

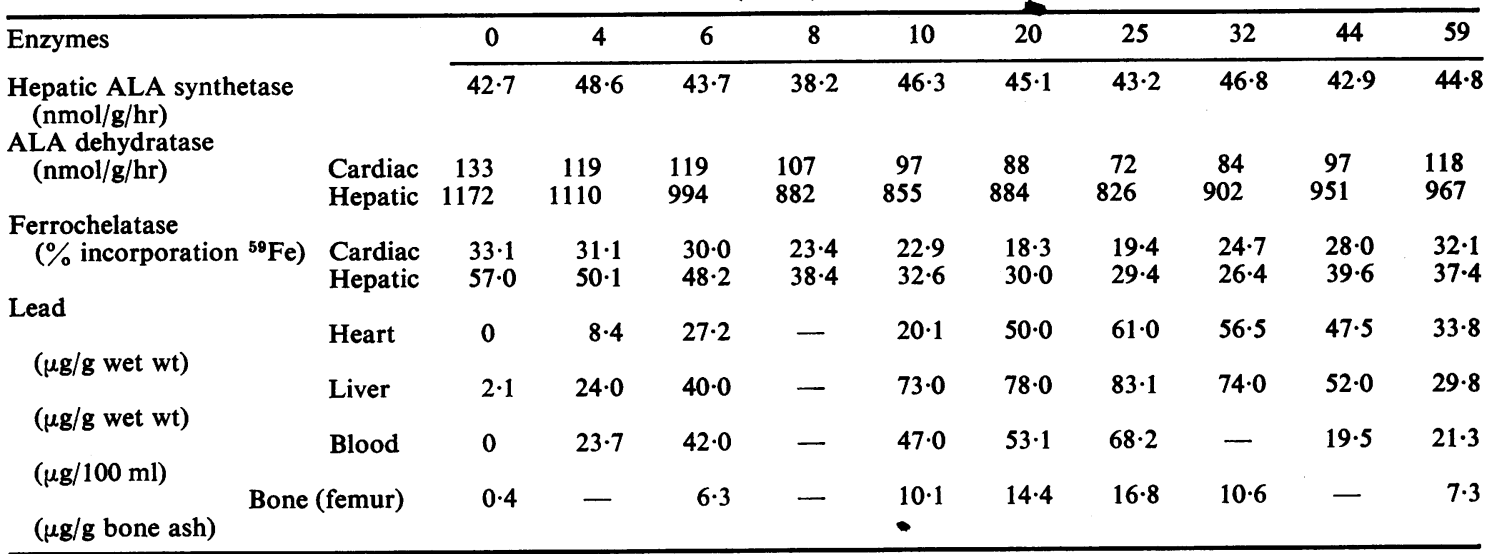


glutaraldehyde, post-fixed in osmium tetroxide and embedded in Araldite. Sections were stained with uranylacetate and lead citrate and examined with a Philips EM 200.

\section{Results}

During the period of the experiment no significant change was observed in hepatic ALA synthetase in any of the groups. There were, however, marked depressions of both cardiac and hepatic ALA dehydratase and ferrochelatase in the 100, 500 and $1000 \mu \mathrm{g} / \mathrm{l}$ groups which became maximal in the $1000 \mu \mathrm{g} / \mathrm{l}$ group after 25 weeks. (Table 1; Fig. 1).

Lead levels showed similar but reversed changes. Lead levels in all tissues rose, reaching plateau levels after about 3 months. In the $1000 \mu \mathrm{g} / \mathrm{l}$ group these levels became maximal after 25 weeks. In this highest dose group, as the lead levels rose so the activities of cardiac and hepatic ALA dehydratase and ferrochelatase fell, rising again after 30 weeks as the lead levels fell. The variations in bone lead are shown in Fig. 2.

It was only in the highest dose group $(1000 \mu \mathrm{g} / \mathrm{l})$ that any ultrastructural changes were observed. In the early stages of the experiment the myocardium of these animals remained within normal limits. At 25 weeks, minor myofibrillar changes became apparent, leading to some loss of structural definition of the myocardium as a whole. In many of the mitochondria, the cristae lost their relatively regular spacing and orientation and showed abnormal clumping, interspersed by areas of rarefaction of the
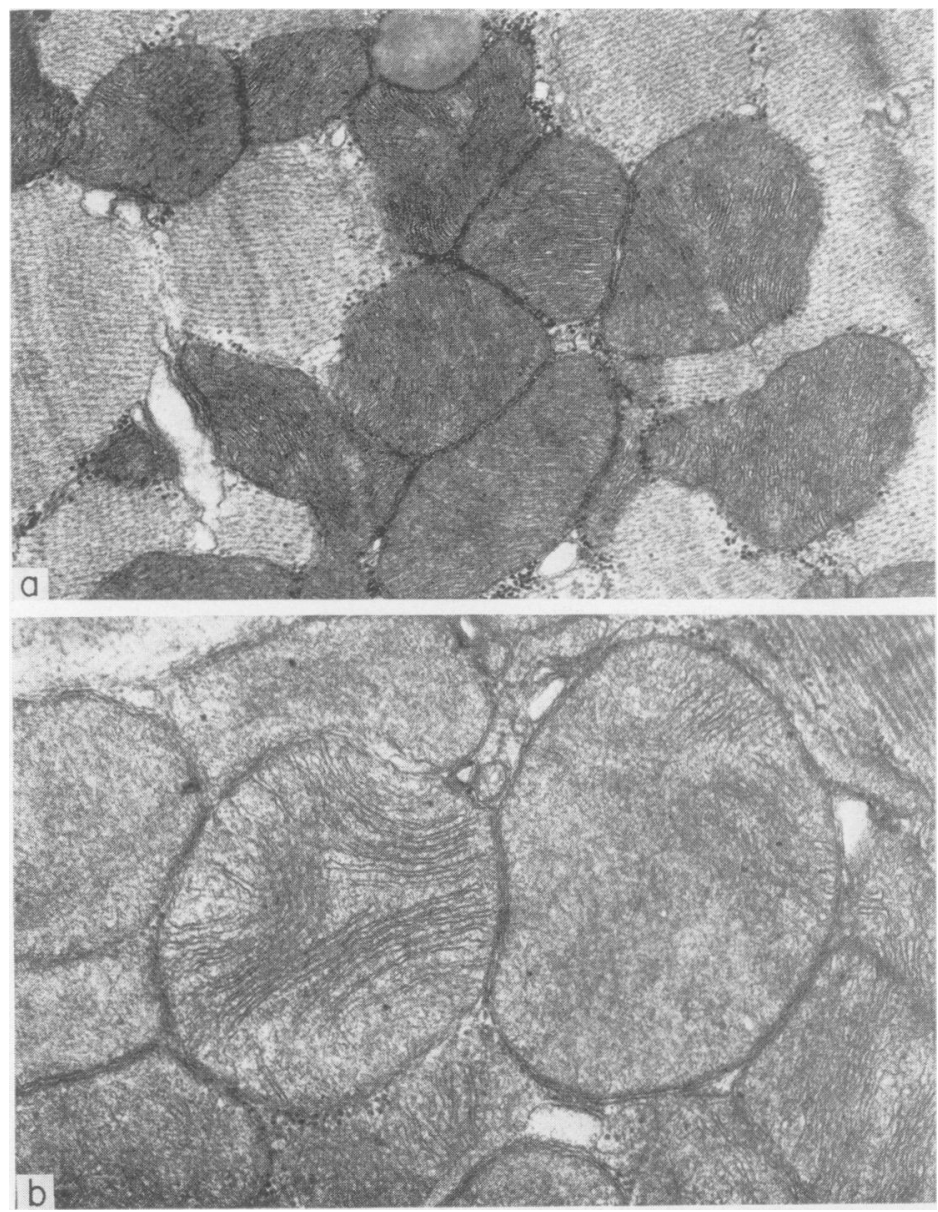

Fig. 3. (a) The structure of normal rat mycocardial mitochondria, showing the regular structure of the cristae and myofibrils. $\times 41,000$. (b) The effect of lead $(1000 \mu \mathrm{g} / \mathrm{l})$ in drinking water for 26 weeks on rat myocardial mitochondria. Note the loss of definition swelling and loss of cristae structure. $x$ 58,000 . 


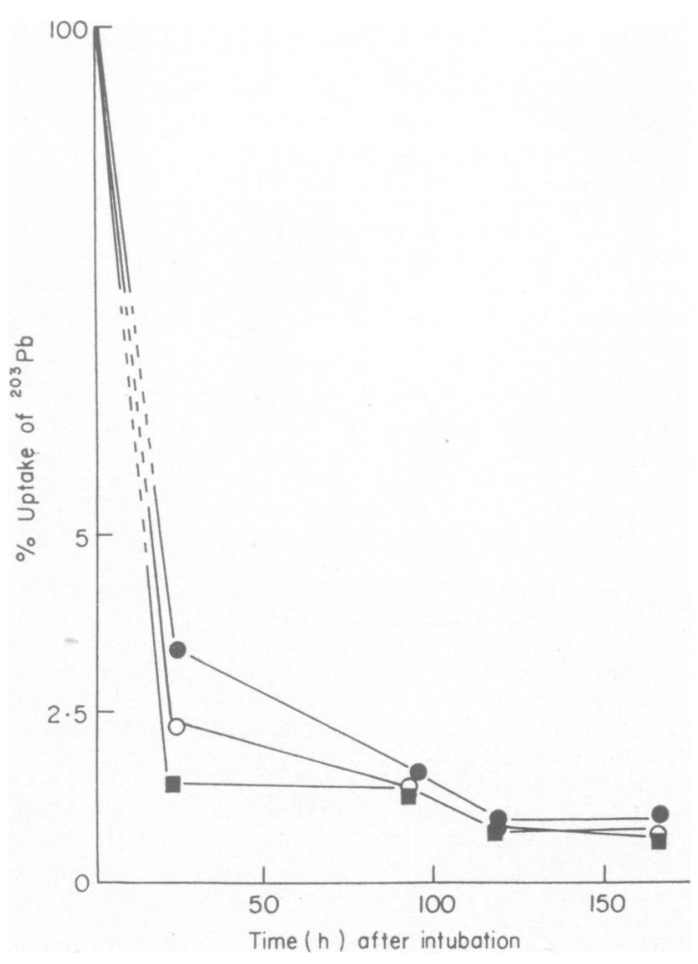

Fig. 4. Oral uptake of ${ }^{203} \mathrm{~Pb}$ chloride into whole animals expressed as $\%$ of phantom after 26 weeks of experiment. control; $\mathrm{O}, \mathrm{Pb}$ acetate $1000 \mu \mathrm{g} / \mathrm{l} ; \mathbf{\mathrm { Q }}, \mathrm{Pb}$ acetate $5000 \mu \mathrm{g} / \mathrm{l}$.

matrix. The mitochondria in general appeared slightly swollen (Fig. 3). It is of note that these changes coincided with the time of maximal biochemical changes (Table 1). After this the biochemical changes became less marked and the fine structure returned to normal.

These elevations of lead levels followed by depression after 25 weeks in the highest dose group suggested variations in the uptake of lead from the gut due to accommodation. For these reasons the uptake of lead by rats treated at $1000 \mu \mathrm{g} / 1$ and $5000 \mu \mathrm{g} / 1$ for 30 weeks was compared with the control lead uptake, using oral ${ }^{203} \mathrm{~Pb}$ chloride. No change was observed in the total uptake of radioactive lead, although there was some variation in the time taken to reach plateau levels (Fig. 4).

Comparison of lead uptake over one week after either oral dosage with $100 \mu \mathrm{Ci}{ }^{203} \mathrm{~Pb}$ chloride or intraperitoneal injection of $50 \mu \mathrm{Ci}{ }^{203} \mathrm{~Pb}$ chloride showed no change in the ratio of uptake into the various organs or into the various subcellular fractions (nuclei, mitochondria, microsomes, or cell sap) as obtained from the liver and heart (Tables 2 \& 3).
TABLE 2. Mean uptake of ${ }^{203} \mathrm{~Pb}$ chloride into various organs of rats 3 days after intraperitoneal injection

\begin{tabular}{lcc}
\hline Organ & \multicolumn{2}{c}{$\begin{array}{c}\% \text { uptake of }{ }^{203} \mathrm{~Pb} \text { into whole organ } \\
\text { with respect to whole body count }\end{array}$} \\
\cline { 2 - 3 } & Control & $\begin{array}{c}\text { Test (1000 } \mu \mathrm{g} \text { Pb acetate in } \\
\text { drinking water for one year) }\end{array}$ \\
\hline Liver & 1.9 & 1.6 \\
Heart & 0.03 & 0.04 \\
Kidneys & 4.7 & 5.1 \\
Spleen & 0.14 & 0.12 \\
Adrenals & 0.003 & 0.004 \\
Lungs & 0.15 & 0.17 \\
Brain & 0.017 & 0.013 \\
Femur & 0.50 & 0.34 \\
\hline
\end{tabular}

TABLE 3. Mean uptake of ${ }^{203} \mathrm{~Pb}$ chloride into myocardium 3 days after intraperitoneal dosage

\begin{tabular}{lcc}
\hline Organelle & $\begin{array}{r}203 \mathrm{~Pb} \% \\
\text { to whole heart counts }\end{array}$ \\
\cline { 2 - 3 } & Control & $\begin{array}{c}\text { Test }(100 \mu \mathrm{g} / \mathrm{l}) \\
\text { for one year }\end{array}$ \\
\hline Nuclei & 4.8 & $4 \cdot 7$ \\
Mitochondria & 1.1 & 1.9 \\
Microsomes & 6.8 & 4.8 \\
\hline
\end{tabular}

\section{Discussion}

Lead has many effects on intermediary metabolis but haem biosynthesis is known to be particularly. of affected (Goldberg 1972). Indeed the activity of the cytoplasmic enzyme $\delta$-aminolaevulinic acid (ALA) dehydratase is taken as a bio-analytical measure of lead exposure.

These results show that there is an association of biochemical change with morphological change in the cardiac muscle of rats treated chronically with lead at $1000 \mu \mathrm{g} / 1$ for 25 weeks, the point at which tissue lead levels are maximal. Biochemical change is not confined to the cytoplasmic enyme ALA dehydratase but is also shown by the mitochondrial enzyme, ferrochelatase, essential for myoglobin production. There are, however, no significant changes in the activity of the other mitochondrial enzyme measured, ALA synthetase, although Edwards and Elliot (1973) have shown an increase in the activity of this enyme in in vitro lead exposure. It is probable that the activity of the other mitochondrial enzyme of the haem biosynthetic pathway, coproporphyrinogen oxidase (EC 1.3.3.3) is also depressed by lead since elevated levels of urinary coproporphyrin excretion are commonly observed in lead poisoning. The ultrastructural changes are seen principally in the myocardial mitochondria. After 30 weeks, lead levels stabilize or (in the highest dose group) drop, enzyme levels, previously depressed, begin to rise and the morphological picture returns to normal. This variation in the levels of 
stored lead could not be readily explained, since there is no apparent change in the oral uptake of tracer doses of lead in these animals after one year, although it could be related to a decreasing alimentary absorption of lead with age (Kostial, Simonović and Pisonić, 1971). There was in addition no alteration in the distribution of lead in the organs.

Similar structural changes have been described by Asokan (1974) who described them as a leadinduced cardiomyopathy. His changes were induced, however, in a shorter, eight-week experiment using the much higher dose level of $1 \%$ lead acetate. In the present experiments significant changes were observed at dose levels considerably lower than this, corresponding to the actual levels recently found in Glasgow water. The significance of these observations may be enhanced by the consideration that only $1 \%$ of ingested lead is absorbed in the rat, whilst in man about $10 \%$ of ingested lead is absorbed. Since lead inhibits cardiac mitochondrial oxidative phosphorylation and therefore mitochondrial respiration (Cardona et al., 1971) thus producing a biochemical ischaemia, this could contribute to the clinical ischaemia produced by atheromatous occlusion of the coronary arteries. These results offer circumstantial evidence to support the view that lead may play some part in the increased mortality due to ischaemic heart disease in soft water areas.

\section{References}

AsoKan, S.K. (1974) Experimental lead cardiomyopathy: myocardial structural changes in rats given small amounts of lead. Journal of Laboratory and Clinical Medicine, 84, 20.

Barltrop, D., Barrett, A.J. \& Dingle, J.T. (1971) Subcellular distribution of lead in the rat. Journal of Laboratory and Clinical Medicine, 77, 705.

Barltrop, D. \& Smith, A. (1972) Lead binding to human haemoglobin. Experientia, 28, 76.
Beattie, A.D., Moore, M.R., Devenay, W.T., Miller, A.R. \& GoldberG, A. (1972) Environmental lead pollution in an urban soft water area. British Medical Journal, 2, 491. Bessis, M. \& BReton Gorius, J. (1959) Ferritin and ferruginous micelles in normal erythroblasts and hypochromic hypersideremic anemias. Blood, 14, 423.

Cardona, E., Lessler, M.A.M. \& Brierly, G.P. (1971) Mitochondrial oxidative phosphorylation: interaction of lead and inorganic phosphate. Proceedings of the Society for Experimental Biology and Medicine, 136, 300.

Castellino, N. \& AloJ, S. (1969) Intracellular distribution of lead in the liver and kidney of the rat. British Journal of Industrial Medicine, 26, 139.

Dowdle, E.B., Mustard, P. \& Eales, L. (1967) Deltaaminolaevulinic acid synthetase acitivity in normal and porphyric human livers. South African Medical Journal, 41, 1093.

EdWardS, A.M. \& Elliot, W.H. (1973) Biochemistry of Gene Expression in high organisms. Ed. J. K. Pollock and J. W. Lee, Australia and New Zealand Book Co., Sidney, 369.

GolDBERG, A. (1972) Lead poisoning and haem biosynthesis. British Journal of Haematology, 23, 521.

Goldberg, A., AshenbruCker, H., Cartwright,-G.W. \& Wintrobe, M.M. (1956) Studies on the biosynthesis of heme in vitro by avian erythrocytes. Blood, 11, 821.

Hasan, J., Vikho, V. \& Hernberg, S. (1967) Deficient red cell membrane/ $\mathrm{Na}^{+} \mathrm{K}^{+} / \mathrm{APT}$ ase in lead poisoning. Archives of Environmental Health, 14, 313.

Kostial, K., Simonović, I. \& Pisonić, M. (1971) Lead absorption from the intestine in newborn rats. Nature. London, 233, 564.

MOORE, M.R. (1973) Plumbosolvency of waters. Nature. London, 243, 222.

Moore, M.R., Beattie, A.D., Thompson, G.G. \& Gold BERG, A. (1971) Depression of delta-aminolaevulinic acid dehydrase activity by ethanol in man and rat. Clinical Science, 40, 81.

Morrow, J.J., Urata, G. \& Goldberg, A. (1969) The effect of lead and ferrous and ferric iron on delta-aminolaevulinic acid synthetase. Clinical Science, 37, 533.

Secchi, G.C., Alessio, L. \& Spreafico, F. (1971) Serum enzymatic activities in experimental lead poisoning. Enzyme, 12, 63.

Stitt, F.W., Crawford, M.D., Clayton, D.G. \& Morris, J.N. (1973) Clinical and biochemical indicators of cardiovascular disease among men living in hard and soft water areas. Lancet, i, 122. 